\title{
Ensino de enfermagem em saúde mental: foco na tecnologia grupal
}

\author{
Nursing teaching in mental health: focus on group technology \\ Enfermería en salud mental: enfoque en tecnología de grupo
}

Recebido: 31/08/2021 | Revisado: 09/09/2021 | Aceito: 13/09/2021 | Publicado: 15/09/2021

\author{
Johnatan Martins Sousa \\ ORCID: https://orcid.org/0000-0002-1152-0795 \\ Universidade Federal de Goiás, Brasil \\ E-mail: johnatanfen.ufg@gmail.com \\ Elizabeth Esperidião \\ ORCID: https://orcid.org/0000-0002-9284-6243 \\ Universidade Federal de Goiás, Brasil \\ E-mail: betesper@ufg.br \\ Fernanda Costa Nunes \\ ORCID: https://orcid.org/0000-0001-5036-648X \\ Faculdade Estácio de Sá, Brasil \\ E-mail: ferdsom@gmail.com \\ Camila Cardoso Caixeta \\ ORCID: https://orcid.org/0000-0003-2479-408X \\ Universidade Federal de Goiás, Brasil \\ E-mail: camilaccaixeta@ufg.br \\ Joyce Soares Silva Landim \\ ORCID: https://orcid.org/0000-0003-1377-9626 \\ Universidade Federal de Goiás, Brasil \\ E-mail: joyceelandim@gmail.com \\ Marciana Gonçalves Farinha \\ ORCID: https://orcid.org/0000-0002-2024-7727 \\ Universidade Federal de Uberlândia, Brasil \\ E-mail:marciana@ufu.br \\ Nathália dos Santos Silva \\ ORCID: https://orcid.org/0000-0001-6667-3951 \\ Universidade Federal de Goiás, Brasil \\ E-mail: nathaliassilva@ufg.br
}

\begin{abstract}
Resumo
Objetivo: descrever a experiência do uso da tecnologia grupal no ensino em saúde mental para Enfermagem, na perspectiva dos docentes. Método: trata-se de um relato de experiência, desenvolvida em $2018 \mathrm{em}$ uma universidade pública da região central do Brasil, de natureza descritiva e feito por docentes. Nesse sentido, a estratégia pedagógica da disciplina de Saúde Mental foi fundamentada nos princípios da Educação de Laboratório e os recursos de aprendizagem utilizados priorizavam as atividades grupais em nove encontros da disciplina. Além disso, as informações analisadas estavam contidas nos diários de campo utilizados pelos docentes para subsidiar o processo de avaliação das estratégias grupais que acontecia durante as reuniões de planejamento, a cada aula, no decorrer das aulas e ao final da disciplina. Resultados: os recursos da tecnologia grupal utilizados foram descritos pelos docentes que observaram e relataram sensibilização para mudança nas atitudes dos alunos, focalização dos princípios da relação de ajuda nas intervenções da Enfermagem, ampliação da autoconfiança e autodescoberta, consequentemente, a competência interpessoal nas relações empreendidas. Conclusão: as experiências grupais ao longo da disciplina permitiram evidenciar a potencialidade da tecnologia grupal para o ensino de saúde mental na perspectiva da compreensão das interações humanas e reflexão dos elementos relacionados à manutenção do bem-estar mental das pessoas.
\end{abstract}

Palavras-chave: Saúde mental; Processos grupais; Enfermagem psiquiátrica; Educação em enfermagem; Docentes de enfermagem; Ensino.

\footnotetext{
Abstract

Objective: to describe the experience of using group technology in teaching mental health for Nursing, from the perspective of teachers. Method: this is an experience report, developed in 2018 at a public university in the central region of Brazil, of a descriptive nature and made by professors. In this sense, the pedagogical strategy of the Mental Health discipline was based on the principles of Laboratory Education and the learning resources used prioritized group activities in nine meetings of the discipline. In addition, the information analyzed was contained in the field diaries used by the professors to support the process of evaluating the group strategies that took place during the
} 
planning meetings, at each class, during classes and at the end of the course. Results: the group technology resources used were described by the professors who observed and reported awareness of changing students' attitudes, focusing on the principles of the helping relationship in Nursing interventions, expanding self-confidence and self-discovery, consequently, interpersonal competence in the relationships undertaken. Conclusion: the group experiences throughout the course made it possible to highlight the potential of group technology for teaching mental health from the perspective of understanding human interactions and reflecting on the elements related to the maintenance of people's mental well-being.

Keywords: Mental health; Group processes; Psychiatric nursing; Education, nursing; Faculty, nursing; Teaching.

\section{Resumen}

Objetivo: describir la experiencia del uso de la tecnología grupal en la enseñanza de la salud mental para Enfermería, desde la perspectiva de los docentes. Método: se trata de un informe de experiencia, desarrollado en 2018 en una universidad pública de la región central de Brasil, de carácter descriptivo y elaborado por profesores. En este sentido, la estrategia pedagógica de la disciplina Salud Mental se basó en los principios de la Educación de Laboratorio y los recursos de aprendizaje utilizados priorizaron las actividades grupales en nueve encuentros de la disciplina. Además, la información analizada fue contenida en los diarios de campo utilizados por los profesores para apoyar el proceso de evaluación de las estrategias grupales que se llevó a cabo durante las reuniones de planificación, en cada clase, durante las clases y al final del curso. Resultados: los recursos tecnológicos grupales utilizados fueron descritos por los profesores que observaron e informaron conciencia de cambio de actitudes de los estudiantes, enfocándose en los principios de la relación de ayuda en las intervenciones de Enfermería, ampliando la autoconfianza y el autodescubrimiento, consecuentemente, la competencia interpersonal en las relaciones emprendidas. Conclusión: las experiencias grupales a lo largo del curso permitieron resaltar el potencial de la tecnología grupal para la enseñanza de la salud mental desde la perspectiva de comprender las interacciones humanas y reflexionar sobre los elementos relacionados con el mantenimiento del bienestar mental de las personas.

Palabras clave: Salud mental; Procesos de grupo; Enfermería psiquiátrica; Educación en enfermería; Docentes de enfermería; Enseñanza.

\section{Introdução}

Com o fenômeno da expansão do ensino superior em âmbito multidisciplinar, a pós-graduação assume importante papel na formação e na inserção de profissionais no campo da docência universitária. Para acompanhar esse movimento, é fundamental o investimento em inovações voltadas para a atuação do professor, rompendo com modelos de aprendizagem que não estimulam a criticidade do aluno (Silva \& Ramos, 2017). Considera-se premente a necessidade do fortalecimento do ensino para que as ações dos enfermeiros não se limitem à medicalização do sofrimento, ao aconselhamento sem aprofundamento e a encaminhamentos dispensáveis para serviços especializados em saúde mental (Nóbrega, Venzel, Sales, \& Próspero, 2020).

Nesse contexto, a abordagem dos conteúdos e as estratégias utilizadas pelos professores sofrem influência de seu próprio processo formativo, além do mais, a intencionalidade de modificação de planos ou a definição de tópicos no sentido de ensinar a especialidade de saúde mental, dentro de uma abordagem generalista, são etapas significativas do processo de ensinar. Dessa maneira, a oferta de educação integrada e a promoção de práticas de aprendizagem diversas perpassam a concepção de sanidade mental que o professor possui e são ferramentas pedagógicas de impacto para a transformação dos processos de trabalho em saúde mental (Rodrigues, Lazzari, Martini, \& Testoni, 2019; Kang \& Joung, 2020).

Dessa forma, quando o professor universitário não recebe durante o seu período de formação uma qualificação direcionada para práticas pedagógicas, o seu desempenho no processo de ensino aprendizagem pode ser prejudicado (Medeiros, Prestes, Pignata, \& Furtado, 2018). Ainda é fundamental que os docentes de Enfermagem estejam atentos à formação da competência humana dos enfermeiros, considerando que não se trata de trabalhar apenas com o conhecimento técnico isoladamente, mas articular o desenvolvimento dos recursos internos do aluno como ser humano. Assim, num mundo dinâmico e versátil, com perfil de geração de alunos e professores em constantes mudanças, é oportuno divulgar práticas pedagógicas, que envolvam tecnologia de grupo, que oportunizam não somente o desenvolvimento de dimensões técnicas, mas de questões intrínsecas ao universo da pessoa (Saeki, Munari, Alencastre, \& Souza, 1999; Nunes, Caixeta, Pinho, Souza, \& 
Barbosa, 2019; Pinho, Nunes, Vale, Sousa, \& Silva, 2019).

Por isso, a atuação do enfermeiro é permeada por atividades coletivas que se iniciam na vida acadêmica por meio da vivência de práticas pedagógicas em grupo (Lima et al., 2018), e se estende para o seu exercício profissional em distintos cenários que demandam atuação com práticas grupais e atividades coletivas em unidade de internação clínica (Kreling \& Magalhães, 2018), em atenção primária à saúde (Brunozzi et al., 2019), em hospital psiquiátrico (Sousa et al., 2018), em contexto assistencial em cardiologia (Arruda et al., 2017) e em Centros de Atenção Psicossocial (Andrade, Farinha, \& Esperidião 2020).

Uma das finalidades da atuação do enfermeiro com atividades em grupos é a reabilitação emocional das pessoas assistidas (Munari \& Furegato, 2003), o que se alinha com a Política Nacional de Saúde Mental que propõe intervenções visando melhores condições de vida com atendimento mais humanizado, reinserção na sociedade a partir de ações no território contando para isso com a participação dos familiares no cuidado integral à pessoa em sofrimento grave e/ou persistente. Para tanto, é preciso compreender o indivíduo em sofrimento como um ser humano em totalidade com sua individualidade inserido em um grupo social (Carvalho, Nantes, \& Costa 2020; Lei n. 10.216, 2001). Vale destacar ainda que, com a orientação dos serviços de saúde organizados em redes de atenção, o cuidado em saúde mental pode ser entendido como uma prática transversal de atuação em todos os contextos de cuidado.

Durante o período de formação profissional é desejável que os docentes estimulem, no decorrer do processo de ensino-aprendizagem, o desenvolvimento de competências voltadas para a assistência integral à saúde do indivíduo, a família e a comunidade, em múltiplos cenários e em contextos de atuação, por meio de estratégias pedagógicas diversificadas que favoreçam a construção do conhecimento. No campo da saúde mental, é ainda mais relevante a necessidade do domínio das tecnologias relacionais ao empreendimento do cuidado aos usuários e aos familiares nos serviços. Enfim, muitas são as ações de cunho coletivo que empregam a tecnologia grupal como estratégia terapêutica importante no modelo de atenção psicossocial (Saeki et al., 1999, Nóbrega et al., 2020; Tavares, Pastor Junior, Paiva, \& Lima, 2021).

Nesta direção, há a necessidade de capacitar os estudantes para exercício da comunicação terapêutica (Jalles, Santos, \& Reinaldo, 2017) e utilização dos recursos da tecnologia grupal. Vale dizer que a tecnologia de grupo é definida como conjunto de teorias, instrumentos, métodos e técnicas do campo da dinâmica de grupo aplicados à assistência em saúde, gestão de pessoas, ensino e pesquisa (Nunes et al., 2019). Tendo em vista o exposto, o presente estudo objetivou descrever a experiência do uso da tecnologia grupal no ensino em saúde mental para Enfermagem, na perspectiva dos docentes.

\section{Metodologia}

Trata-se de um relato de experiência de natureza descritiva sobre o uso da tecnologia grupal (Nunes et al., 2019) na disciplina Saúde Mental do Curso de Graduação em Enfermagem, de uma universidade pública do centro-oeste brasileiro, desenvolvida no segundo semestre letivo de 2018, totalizando 17 encontros presenciais e cinco atividades extraclasses. Participaram da disciplina seis alunos regularmente matriculados, duas docentes e um mestrando que fazia estágio de docência, também pós-graduando em Dinâmica de Grupo e Gestão de Equipes.

Destaca-se que o relato das experiências foi descrito com base nas discussões entre os docentes que eram feitas em reuniões de planejamento das aulas e após a finalização de cada uma delas e de notas dos docentes feitas em diário de campo sobre o processamento das técnicas durante as aulas. As informações contidas nos diários de campo dos docentes foram utilizadas para subsidiar o processo de reflexão/avaliação das estratégias grupais durante as reuniões de planejamento e avaliação de cada aula e ao final da disciplina.

A disciplina Saúde Mental, com carga horária de 48 horas, tem como objetivo geral desenvolver competências para a compreensão das interações humanas e os elementos relacionados à manutenção da saúde mental das pessoas. Trabalha 
tecnologias leves nas ações de enfermagem, foca no reconhecimento das características de crises existenciais, na reflexão do autoconhecimento como estratégia facilitadora no cuidado humanizado, identificando os pressupostos fundamentais da relação de ajuda, além de adotar os fundamentos do Relacionamento Interpessoal (Pinheiro, Araújo, Rolim, Oliveira, \& Alencar, 2019) como suporte das ações de enfermagem.

Com a perspectiva de proporcionar aprendizagem significativa e de criar momentos interativos entre os participantes, utilizaram-se variadas estratégias de aprendizagem, priorizando a tecnologia de grupo (Nunes et al., 2019). Além de aulas expositivo-dialogadas e mapas conceituais, aconteceram rodas de conversa, seminários criativos de cunho teórico-práticos, culminando com a elaboração de uma proposta de intervenção em saúde mental no contexto das vivências acadêmicas dos alunos no semestre.

Ademais, todas as aulas da disciplina foram planejadas considerando os princípios da Educação de Laboratório almejando transformações a partir de aprendizagens ancoradas em vivências alinhadas à metodologia do Ciclo da Aprendizagem Vivencial, que é composto por quatro componentes. Inicialmente, a atividade é implementada por meio de uma vivência mediada por várias estratégias como jogos, dramatizações, entre outros, depois o componente é a análise, que diz respeito ao processo diagnóstico do que foi vivenciado por meio de discussões do que foi realizado, em seguida, acontece a fase da conceituação, caracterizada pela oferta de fundamentação teórica em relação à temática abordada e por fim, a conexão, que possibilita com que os participantes do processo vivencial correlacionem o que foi experienciado com a sua realidade (Moscovici, 2008).

Por fim, o planejamento considerava um primeiro momento de acolhimento do aluno, pois tinha caráter de um encontro didático-pedagógico, em que por meio da escuta realizaria também a sensibilização para o tema da aula, num nítido movimento do processo interativo entre os participantes; em seguida a realização de uma técnica ou vivência grupal relacionada à temática a ser discutida e, por fim, o encerramento reflexivo para construção de possíveis conexões do vivido ao contexto concreto da realidade de vida das pessoas. O Quadro 1 descreve as estratégias grupais utilizadas no decorrer da disciplina.

Quadro 1. Estratégias grupais utilizadas em cada encontro no decorrer da disciplina Saúde Mental. Goiânia, Goiás, Brasil, 2018.

\begin{tabular}{|c|c|c|c|}
\hline Encontro & Objetivo & Estratégia & Descrição da atividade \\
\hline $1^{\circ}$ & $\begin{array}{l}\text { Realizar o acolhimento } \\
\text { dos alunos e a interação } \\
\text { com o grupo }\end{array}$ & $\begin{array}{l}\text { "Te recebo, te dou } \\
\text { espaço e caminhamos } \\
\text { juntos" } \\
\text { (Rosseto, 2012) }\end{array}$ & $\begin{array}{l}\text { Posicionados em círculo, cada integrante do grupo se apresentou, } \\
\text { dizendo seu nome e após, todos repetiam juntos a expressão: "Te } \\
\text { recebo, te dou espaço e caminhamos juntos". }\end{array}$ \\
\hline $2^{\circ}$ & $\begin{array}{l}\text { Conhecer a percepção } \\
\text { dos alunos sobre saúde } \\
\text { mental }\end{array}$ & $\begin{array}{l}\text { Reflexão: } \\
\text { "O que é saúde mental } \\
\text { para você??" }\end{array}$ & $\begin{array}{l}\text { Os alunos foram divididos em duplas para que construíssem um } \\
\text { painel norteados pela pergunta "O que é saúde mental para você?? } \\
\text { Foram disponibilizados cartolinas, tesouras, revistas, canetas, lápis, } \\
\text { giz de cera, canetinhas coloridas e cola para esta tarefa, que foi } \\
\text { socializada para todo o grupo, seguida de um debate. }\end{array}$ \\
\hline $3^{\circ}$ & $\begin{array}{l}\text { Vivenciar uma relação } \\
\text { de ajuda como } \\
\text { mecanismo de cuidado } \\
\text { em saúde mental }\end{array}$ & $\begin{array}{l}\text { "Improvisação } \\
\text { teatral" } \\
\text { (Rosseto, 2012) }\end{array}$ & $\begin{array}{l}\text { O grupo teria que encenar uma situação de relação de ajuda, } \\
\text { estando livre para definir os personagens e os demais recursos } \\
\text { lúdicos a serem utilizados. }\end{array}$ \\
\hline $7^{\circ}$ & $\begin{array}{l}\text { Situar os alunos no aqui } \\
\text { e agora, promover } \\
\text { relaxamento e estimular } \\
\text { a concentração e } \\
\text { percepção sensorial }\end{array}$ & $\begin{array}{c}\text { "Audição musical” } \\
\text { (Queiroz, 1997) }\end{array}$ & $\begin{array}{l}\text { Com a sala em meia luz, os alunos eram encorajados a ficar com os } \\
\text { olhos fechados e respirando de forma lenta e ritmada para que } \\
\text { pudessem sentir e perceber o próprio corpo. Enquanto que um dos } \\
\text { professores disparava os sons de fogo em lareira, de chuva caindo } \\
\text { na terra, de vento em uma varanda e de uma cachoeira. Após esse } \\
\text { processo, os alunos teriam que tentar identificar o que ouviram. }\end{array}$ \\
\hline
\end{tabular}




\begin{tabular}{|c|c|c|c|}
\hline $7^{\circ}$ & $\begin{array}{l}\text { Sensibilizar os alunos } \\
\text { para suas competências } \\
\text { interpessoais por meio } \\
\text { do autoconhecimento } \\
\text { de aspectos de sua } \\
\text { personalidade }\end{array}$ & $\begin{array}{l}\text { "Tetragrama dos } 4 \\
\text { elementos" } \\
\text { (Gramigna, 2016) }\end{array}$ & $\begin{array}{l}\text { Cada aluno recebeu um formulário para assinalar, a partir das } \\
\text { características dos quatro elementos da natureza: ar, fogo, água e } \\
\text { terra, seus pontos fortes, sua forma de agir e aspectos a serem } \\
\text { fortalecidos, procurando identificar formas de melhorar os } \\
\text { relacionamentos profissionais e pessoais. }\end{array}$ \\
\hline $10^{\circ}$ & $\begin{array}{l}\text { Debater a criatividade e } \\
\text { concepções do trabalho } \\
\text { em grupo/equipe } \\
\text { enquanto instrumentos } \\
\text { básicos do cuidar }\end{array}$ & $\begin{array}{l}\text { "O Guia de cego" } \\
\text { (Miranda, 2012) }\end{array}$ & $\begin{array}{l}\text { Os alunos foram divididos em duplas e deveriam escolher uma } \\
\text { pessoa para ficar vendada, enquanto a outra iria guiá-la pela sala } \\
\text { somente com a vocalização de uma palavra também elencada por } \\
\text { eles. Dever-se-ia evitar que o colega encostasse nos demais alunos } \\
\text { que também faziam o mesmo trajeto. Em seguida, os papéis eram } \\
\text { invertidos, e por fim, o grupo deveria escolher uma pessoa que } \\
\text { seria o líder e os conduziriam vendados por meio de palpação. }\end{array}$ \\
\hline $11^{\circ}$ & $\begin{array}{l}\text { Refletir o planejamento } \\
\text { de possíveis ações a } \\
\text { partir da observação da } \\
\text { realidade e definição } \\
\text { dos nós críticos }\end{array}$ & $\begin{array}{l}\text { "Lego serious play" } \\
\text { (Souza, 2017) }\end{array}$ & $\begin{array}{l}\text { A técnica exigia a construção de uma estrutura física de um espaço, } \\
\text { utilizando blocos de encaixar. A sugestão era que reconstruíssem o } \\
\text { espaço físico da instituição de ensino onde eles estudam. }\end{array}$ \\
\hline $12^{\circ}$ & $\begin{array}{l}\text { Estimular a reflexão } \\
\text { para a identificação de } \\
\text { questões que } \\
\text { influenciam a saúde } \\
\text { mental dos alunos }\end{array}$ & $\begin{array}{l}\text { "Chuva de ideias" } \\
\text { (Afonso, 2003) }\end{array}$ & $\begin{array}{l}\text { Os professores da disciplina faziam perguntas disparadoras para } \\
\text { que os alunos verbalizassem situações-problemas que afetem sua } \\
\text { saúde mental para, posteriormente, elaborarem uma proposta de } \\
\text { intervenção com vistas ao enfrentamento dos fatores elencados. Foi } \\
\text { solicitado que ao refletirem o exposto, destacassem três problemas } \\
\text { prioritários a serem focados na intervenção. }\end{array}$ \\
\hline $16^{\circ}$ & $\begin{array}{l}\text { Refletir sobre a } \\
\text { importância do } \\
\text { autocuidado }\end{array}$ & $\begin{array}{l}\text { "Roda da vida" } \\
\text { (Fundação estudar, } \\
\text { 2020) }\end{array}$ & $\begin{array}{l}\text { Em um formulário preenchiam por meio de pintura com lápis de } \\
\text { cor um espaço que atribuía uma nota de } 0 \text { a } 10 \text { para cada aspecto da } \\
\text { vida (lazer; saúde e condição física; relacionamento e amigos; } \\
\text { romance e relação íntima; família; bem-estar psicológico; } \\
\text { espiritualidade; estudos, intelectualidade e qualificação; } \\
\text { trabalho/profissional; financeiro e dinheiro). }\end{array}$ \\
\hline $17^{\circ}$ & Avaliar a disciplina & $\begin{array}{l}\text { "Que bom, que pena e } \\
\text { que tal?" } \\
\text { (Berkenbroc, 2015) }\end{array}$ & $\begin{array}{l}\text { Por meio das questões: que bom, que pena e que tal? Cada aluno } \\
\text { verbalizou a sua avaliação do conteúdo, estratégias pedagógicas e } \\
\text { contribuição da disciplina para a sua formação crítico-reflexiva. }\end{array}$ \\
\hline
\end{tabular}

Fonte: Sistematização própria

\section{Resultados}

A apresentação dos membros de um grupo é etapa fundamental no sentido de estabelecer as características e o perfil da configuração do coletivo, no qual se incluem os facilitadores, ainda que talvez alguns se conheçam de outros contextos. Por meio da técnica "Te recebo, te dou espaço e caminhamos juntos" (Rosseto, 2012), os participantes posicionados em círculo, cada um se apresentou. Neste momento foi estimulado o processo de autopercepção e de percepção do outro por meio da escuta, e diante das frases de acolhimento, emergiram sorrisos e trocas de olhares, favorecendo quebra gelo e iniciação de um clima relacional e construção de vínculo entre docentes e alunos.

No segundo encontro da disciplina, por meio da técnica “O que é saúde mental para você??", os alunos associaram o tema saúde mental com o bem-estar, sentimentos de segurança, momentos de lazer, estar com amigos e família, cultivo da autoestima e autoaceitação, afeto, além do prazer de usufruir de comidas saborosas. Em seguida, os conteúdos foram problematizados para o panorama de cuidado, procurando identificar aspectos sócio, político e econômicos que afetam a saúde mental do ser humano. Essa técnica foi importante, pois valorizou o conhecimento prévio dos alunos, fazendo com que eles se tornassem protagonistas no processo de ensino-aprendizagem.

No terceiro encontro, por meio da técnica da "Improvisação teatral" (Rosseto, 2012) de uma cena de Relação de Ajuda, os estudantes puderam trabalhar a espontaneidade e formularam a encenação de práticas de cuidado entre profissional 
de enfermagem e de usuário do Sistema Único de Saúde (SUS). Foi possível ainda trabalhar questões emocionais como o exercício da empatia e timidez, pois o trabalho grupal por meio da dramatização de outros personagens os deixaram desinibidos diante dos colegas da turma. A partir da riqueza da cena e dos encaminhamentos despontados, ao final foi possível destacar os princípios teóricos que fundamentam a Relação de Ajuda, enquanto prática de cuidado para pessoas com alguma necessidade de suporte emocional.

No sétimo encontro, na etapa de processamento da técnica "Audição musical" (Queiroz, 1997), os alunos passaram a verbalizar a experiência vivida. Visualmente eles aparentavam mais serenidade e quietude na expressão após o momento de introspecção, concentração na tarefa, pois todos conseguiram identificar os sons dos elementos que estavam sendo representados no áudio. Foi intensamente refletida a importância da competência do autoconhecimento para o desenvolvimento pessoal e profissional. Tornou-se oportuno também reconhecer as formas de agir dos outros integrantes do grupo, sensibilizando-os para a questão do respeito à individualidade, aspecto relevante para as práticas de cuidado no cenário da saúde. E por meio do "Tetragrama dos 4 elementos" (Gramigna, 2016), os alunos puderam perceber aspectos das suas personalidades e seus pontos fortes para o trabalho multiprofissional, reconhecendo a importância de se conhecer e respeitar as diferenças dos outros.

No décimo encontro, ao final da técnica "O Guia de cego" (Miranda, 2012), os alunos verbalizaram as facilidades e as dificuldades em serem conduzidos por outras pessoas, além de aspectos relativos à confiança, revelando muito do funcionamento pessoal e da história de vida de cada um. Quanto à escolha do "líder", tanto o líder eleito pelo grupo, quanto os demais participantes manifestaram ter sido um processo natural e tranquilo, sem resistências ou conflitos aparentes. Nessa direção, o exercício oportunizou a percepção da liderança e do trabalho em equipe, enquanto elementos fundamentais para enfermagem, que articula seu trabalho com outros profissionais e precisam destes instrumentos do cuidar para a eficiência na gestão de recursos humanos e dos serviços de saúde.

No décimo primeiro encontro, a necessidade da discussão em grupo do contexto, conhecimento e planejamento de possíveis ações por meio do "Lego serious play" (Souza, 2017) ficou evidente. Neste momento foram manifestados sentimentos de insegurança e de medo em não conseguirem executar a atividade com iniciativas individuais, mas que foram superados por meio do trabalho em equipe e cooperação mútua. Entretanto, foi possível observar habilidades individuais de alguns participantes em que um aluno fez um esquema por meio de desenho para facilitar o planejamento, outro ditava uma sequência lógica para a representação, outros realizaram a parte manual e também se atentaram para que as estruturas mais importantes da universidade estivessem presentes no esquema. Evidenciou-se a importância do planejamento enquanto estratégia basilar quando se pretende ter êxito em uma empreitada.

No décimo segundo encontro, a técnica "Chuva de ideias" (Afonso et al., 2003) estimulou o potencial de reflexão dos alunos, direcionando o olhar crítico para a própria realidade, aspecto fundamental para a transformação de forma concreta diante do diagnóstico situacional encontrado. Foi possível elencar vários elementos que afetam a saúde mental dos alunos: relacionamento interpessoal ineficaz entre professores e alunos, grande competitividade no meio acadêmico, sobrecarga de atividades acadêmicas, dificuldades de administração do tempo, ausência de um espaço para descanso nas dependências da universidade com horários flexíveis para a utilização, reprovação como motivação para o uso de álcool e outras drogas, falta de didática por parte de alguns professores, falta de acolhimento de alunos lésbicas, gays, bissexuais, transgêneros, queer, intersexuais, assexuados e outros (LGBTQIA+), pouco acolhimento das especificidades do aluno trabalhador, falta de apoio psicológico e acúmulo de matérias no mesmo período.

No décimo sexto encontro, o recurso da "Roda da Vida" (Fundação Estudar, 2020) oportunizou aos alunos olharem para si e perceberem quais áreas de suas vidas, naquele momento, precisavam de maior atenção e cuidado. Cada um verbalizou os aspectos que necessitavam de maior atenção para que a roda da vida de cada um pudesse girar de forma harmônica. Durante 
o processamento, vários aspectos foram apontados como frágeis, revelando que esse processo de autopercepção é importante para tentar encontrar o equilíbrio e bem-estar dos alunos. Assim, a reflexão favoreceu reforçar a necessidade do autocuidado, a despeito de que enquanto estudantes de enfermagem que prestam cuidados ao outro, precisam também se atentar para si próprio.

Para finalizar e ponderar todo o processo vivido ao longo do semestre, foi feita a avaliação do conteúdo, das estratégias pedagógicas e da contribuição da disciplina para a formação crítico-reflexiva por meio das questões: "que bom, que pena e que tal?" (Berkenbroc, 2015). As estratégias pedagógicas foram consideradas adequadas para o aprendizado do conteúdo e positivas no processo de autoavaliação do desempenho, além de favorecer a percepção da procrastinação como uma questão que tem dificultado o desempenho acadêmico e, por consequência, aumentando a ansiedade. Perceberam o conteúdo da disciplina como transversal e necessário à formação e atuação profissional humanista e interpessoal, ressaltaram que o número reduzido de alunos matriculados na disciplina não favoreceu a intervenção proposta no $12^{\circ}$ encontro e sugeriram que este número deva ser ampliado.

\section{Discussão}

No primeiro encontro da disciplina de saúde mental, a técnica "Te recebo, te dou espaço e caminhamos juntos" (Rosseto, 2012) propiciou acolhimento e foi um mecanismo disparador e foi mediador da interatividade entre todos os membros do grupo por meio da fala e da escuta. Efetivamente, o acolhimento é requisito essencial em qualquer ambiente que lida com recursos humanos e a escuta é uma ferramenta imprescindível nesse processo nos mais diversificados cenários. $\mathrm{O}$ ato de acolher é construído à medida que o intercâmbio de experiências e sentimentos acontece, por isso, a escuta deve ser alicerçada em respeito e humanização (Assis et al., 2020).

No segundo encontro, com o emprego da técnica "O que é saúde mental para você??", os alunos mergulharam em seu mundo interior e expuseram as suas ideias sobre o que é saúde mental. Isso porque, o processo de ensino-aprendizagem na graduação exige a necessidade de instrumentalizar os estudantes para a atuação em diferentes frentes de trabalho. Na Saúde Mental, por exemplo, trazer o acadêmico de enfermagem para refletir sobre as suas questões emocionais antes de aprender a cuidar do outro, seu futuro cliente/paciente, em seu processo de aprendizagem profissional é essencial (Rocha, Kestenberg, Oliveira, Silva, \& Nunes, 2003).

No terceiro encontro, houve o emprego de recursos cênicos no contexto da sala aula por meio da estratégia "Improvisação teatral" (Rosseto, 2012). Essa técnica permitiu aos alunos colocassem em prática a criatividade para explorarem o tema da relação de ajuda realizada pelo enfermeiro no cuidado em saúde mental aos usuários dos serviços de saúde. É fundamental instrumentalizar os alunos não só com a técnica, mas também com a competência emocional, como saber identificar e lidar com suas próprias emoções e com a do outro. Em uma sala de aula é comum ter alunos com maior habilidade para as interações interpessoais do que outros, porém é possível desenvolver ou aprender competências relacionais (Rocha et al., 2003).

Em uma pesquisa de revisão da literatura, com o objetivo de compreender o que os estudos científicos trazem sobre a relação de ajuda nas intervenções da Enfermagem, obteve que o profissional enfermeiro executando a relação de ajuda deve focar na capacidade de escuta, empatia, aceitação e respeito. Por isso, o estudo enfatiza que esta estratégia pode ser útil em situações de ansiedade, tristeza e luto e as intervenções devem ser pautadas na escuta ativa (Coelho et al., 2020).

No sétimo encontro, a técnica “Audição musical” (Queiroz, 1997) promoveu relaxamento aos estudantes por meio da sensibilidade auditiva dos sons da natureza, se mostrando promissora. Isso é significativo porque o ambiente universitário simboliza o início da trajetória profissional para os estudantes, porém, um grupo numeroso deste público assume uma dupla jornada, conciliando os estudos com o trabalho, o que pode acarretar sobrecarga de atividades e prejuízos tanto na saúde física, 
quanto mental desses discentes (Freitas et al., 2018). Dessa forma, iniciativas que inserem estratégias de relaxamento e de atenção plena em sala de aula tem o poder de minimizar esses danos e estimular a reflexão de possibilidades de enfrentamento.

Neste mesmo encontro, a técnica do "Tetragrama dos 4 elementos" (Gramigna, 2016) ajudou os alunos a reconhecerem suas potencialidades, fazendo alusão às características do ar, fogo, água e terra, e também puderam trabalhar questões referentes aos relacionamentos interpessoais, aumentando o autoconhecimento. Entende-se que a competência interpessoal passa, inevitavelmente, pela experimentação, em que vai se desenvolvendo essa habilidade. Esse processo ocorre a partir das relações estabelecidas com os outros, fazendo-se primordial criar espaços para os graduandos vivenciarem e se aperfeiçoarem a auto percepção e construírem seu fazer não apenas pelo que o docente fala que é correto, mas pelo que ele experienciou e compreendeu como importante (Munari, Costa, Cardoso, \& Almeida, 2003).

A técnica do "O Guia de cego" (Miranda, 2012) permitiu aos alunos que problematizassem a temática sobre liderança e trabalho em equipe na atuação do enfermeiro. Isso porque, o enfermeiro é um profissional que exerce liderança nos diversos cenários de sua atuação, por isso, é importante que se desenvolva essa competência interpessoal durante o seu período de formação para facilitar e para otimizar os processos gerenciais para o diagnóstico e resolução de problemas (Munari et al., 2003).

Outra competência fundamental para a prática de enfermagem é o trabalho em equipe, o que exige uma formação que contemple essa necessidade (Munari et al., 2003). O trabalho em equipe para ser operacionalizado exige competência, que consiste em um conjunto de conhecimentos, habilidades e atitudes de todos os envolvidos no processo, sem excluir a individualidade e subjetividade de cada pessoa, que carrega consigo a sua história de vida que influencia no trabalho em coletividade (Guimarães, Garanhani, Souza, \& Haddad, 2018).

O emprego da técnica "Lego serious play" (Souza, 2017) possibilitou reflexões no grupo sobre a importância do planejamento e da sistematização das ações realizadas pelo enfermeiro para a realização de tarefas e resolução de problemas que emergem. No ambiente da sala de aula é necessário ofertar aos alunos momentos que os direcionam para a resolução de problemas aliado à construção de saberes para facilitar o desenvolvimento intelectual e pessoal (Caetano, 2017). Nessa perspectiva, a aprendizagem vivencial é uma abordagem que favorece o engajamento dos alunos no processo de ensino em saúde mental (Mendes, Marques, Monteiro, Barroso, \& Quaresma, 2018).

O uso da estratégia da "Chuva de ideias" (Afonso, 2003) ajudou aos alunos a refletir sobre a descoberta de fenômenos que afetam a sua saúde mental no contexto acadêmico e colaborou para busca de alternativas para a sua resolução. Tudo isso, é confirmado por um estudo desenvolvido em uma instituição pública do Estado do Paraná, que a atividade acadêmica pode ser uma fonte de estresse, ao caracterizar 73,7\% dos alunos do curso de Enfermagem em alguma fase desse estado (Santana et al., 2018). Portanto, os inúmeros desafios que os estudantes universitários são expostos e as repercussões negativas advindas dessas constatações, ações interventivas para minimizar o estresse dos acadêmicos com o objetivo de promover uma melhor qualidade de vida desse público são muito pertinentes e bastante relevantes (Ward-Griffin et al., 2018).

A implementação da "Roda da vida" (Fundação Estudar, 2020) junto aos alunos fez com que eles reconhecessem as dimensões da sua vida que precisavam de um maior investimento, e trouxe para discussão a importância do autocuidado. Uma investigação científica que utilizou os recursos da Roda da Vida com a finalidade de desenvolver a liderança de enfermeiros que atuavam na Atenção Primária à Saúde apontou que esta ferramenta favoreceu o autoconhecimento dos participantes da pesquisa e tomada de consciência dos aspectos da vida que precisam ser trabalhados (Rocha, Munari, Sousa, Leal, \& Ribeiro, 2019), o que vai ao encontro dos achados desta experiência.

No último encontro, a técnica "Que bom, que pena e que tal?" (Berkenbroc, 2015), por ser uma maneira distinta das demais formas de avaliação, promoveu um maior envolvimento dos graduandos no processo avaliativo. A avaliação é uma das etapas mais complexas do processo de ensino-aprendizagem na educação de nível superior e deve levar em consideração as 
particularidades do grupo de alunos que é composto por jovens e adultos (Pedrochi Júnior, Carvalho, Silva, \& Costa, 2021).

Dessa forma, especialmente na enfermagem, a avaliação deve ser alicerçada no desenvolvimento de competências para a formação profissional que atenda as demandas de saúde da comunidade, mesmo existindo uma gama extensa de métodos avaliativos, é importante avaliar as suas especificidades para a escolha mais assertiva que atenda aos objetivos de aprendizagem idealizados e com as competências apreendidas (Belém, et al., 2018).

\section{Conclusão}

Os recursos relativos à dinâmica de grupo possibilitaram abordar diversos temas do campo da saúde mental em vários cenários, além do desenvolvimento de competências interpessoais para o exercício da Enfermagem, englobando o cuidado, a gestão e o ensino. Ademais, as experiências grupais ao longo da disciplina permitiram a compreensão das interações humanas refletindo os elementos relacionados à manutenção da saúde mental das pessoas, além de oportunizar o autoconhecimento, a expressão e o acolhimento de sentimentos e emoções sentidos pelos alunos durante as práticas de cuidado.

Neste contexto, a experiência foi fortalecer as atividades teórico-práticas por meio de vivências no próprio grupo de alunos que experimentaram situações do cotidiano em pertinência com os objetivos traçados. Assim, os aspectos relacionais e emocionais são o foco nas interações entre os alunos e o trabalho em equipe, procurando sensibilizá-los acerca da importância do desenvolvimento da competência interpessoal para o estabelecimento da relação de ajuda nos diversos cenários de cuidado e atuação do enfermeiro.

A principal limitação durante a experiência foi o pequeno número de alunos matriculados na disciplina. Reconhecemos que, apesar de um grupo pequeno de alunos favorecer o processo grupal, pode comprometer a realização de algumas técnicas. Além disso, a maioria das referências das estratégias utilizadas foram extraídas em sua maioria de livros e sites, o que reforça a importância e inovação da publicação de artigos científicos que abordem a utilização desses recursos no contexto não somente do ensino, mas também no cenário assistencial e gerencial.

Diante do exposto, a socialização da experiência vivenciada contribuiu para a academia, pois indica que o conteúdo da disciplina Saúde Mental e a utilização de técnicas e vivências grupais, como estratégia pedagógica, provocaram nos alunos autorreflexão e autoconhecimento. Assim, houve uma contribuição para o acolhimento dos sentimentos de insegurança e de medo de falharem na execução das atividades ou não superarem as situações de dor e de sofrimento vivenciados nas práticas de cuidado em outras disciplinas do curso de enfermagem.

\section{Referências}

Afonso, L., Abade, F. L., Akerman, D., Coelho, C. M. S., Medrado, K. S., Paulino, J. R., \& Pimenta, S. D. C. (2003). Oficinas em dinâmica de grupo na área da saúde. Casa do Psicólogo.

Andrade, J. M. M., Farinha, M. G., \& Esperidião, E. (2020). Enfermagem em Saúde Mental: intervenção em sala de espera na assistência integral à saúde. Revista Brasileira de Enfermagem, 73(Suppl 1), e20180886. 10.1590/0034-7167-2018-0886

Arruda, C. S., Pereira, J. M. V., Figueiredo, L. S., Scofano, B. S., Flores, P. V. P., \& Cavalcanti, A. C. D. (2017). Effect of an orientation group for patients with chronic heart failure: randomized controlled trial. Revista Latino Americana de Enfermagem, 25(e2982):01-09. 10.1590/1518-8345.2167.2982

Assis, A. D., Magalhães, C. V. A., Vaz, D. L. M., Santos, É. D. P., Oliveira, L. C. D., Torres I. H., \& Brito, P. O. A. (2020). ACALENTO: grupo de acolhimento virtual dos profissionais de saúde de Ouro Preto, Minas Gerais. Raízes e Rumos, 8(1), 202-212. Recuperado de: Vista do ACALENTO: grupo de acolhimento virtual dos profissionais de saúde de Ouro Preto, Minas Gerais. (unirio.br).

Belém, J. M., Alves, M. J. H., Quirino, G. S., Maia, E. R., Lopes, M. S. V., \& Machado, M. F. A. S. (2018). Avaliação da aprendizagem no estágio supervisionado de enfermagem em saúde coletiva. Revista Trabalho, Educação e Saúde, 16(3), 849-867. 10.1590/1981-7746-sol00161

Berkenbrock, V. J. (2015). Dinâmicas para encontros de grupo: para apresentação, intervalo, autoconhecimento e conhecimento mútuo, amigo oculto, despertar, avaliação e encerramento. (13a ed.) Editora Vozes.

Brunozzi, N. A., Souza, S. S., Sampaio, C. R., Maier, S. R. O., Silva, L. C. V. G., \& Sudré. G. A. (2019). Grupo terapêutico em saúde mental: percepção de usuários na atenção básica. Revista Gaúcha de Enfermagem, 40(e20190008), 01-09. 10.1590/1983-1447.2019.20190008 
Caetano, A. B. J. R. (2017). Estratégias de aprendizagens ativas em estudantes de Enfermagem: Aprendizagem cooperativa e resolução de problemas. Indagatio Didactica, 9(1):38-50. Estratégias de aprendizagens ativas em estudantes de Enfermagem: Aprendizagem cooperativa e resolução de problemas (1library.org).

Carvalho, R. C. N., Nantes, R. F. P., \& Costa, M. L. (2020). Estratégia familiar de cuidado em saúde mental. Brazilian Journal of Development, 6(7), 5025650271. 10.34117/bjdv6n7-615

Coelho, J., Sampaio, F., Teixeira, S., Parola, V., Sequeira, C., Fortuño, M. L., \& Merino, J. R. (2020). A relação de ajuda como intervenção de enfermagem: Uma scoping review. Revista Portuguesa de Enfermagem de Saúde Mental, (23), 63-72. 10.19131/rpesm.0274

Freitas, A. C. M., Malheiros, R. M. M., Lourenço, B. S., Pinto, F. F., Souza, C. C., \& Almeida, A. C. L. (2018). Fatores intervenientes na qualidade de vida do estudante de enfermagem. Revista de Enfermagem UFPE on line, 12(9), 2376-85. 10.5205/1981-8963-v12i8a230110p2376-2385-2018

Fundação Estudar. (2021). Roda da Vida: a ferramenta de autoconhecimento que serve para a carreira e vida pessoal. Roda da Vida: o que é, como funciona e modelo para baixar (napratica.org.br).

Gramigna, M. R. (2016). Tetragrama: uma ferramenta coaching por competências. Tetragrama - Uma Ferramenta Do Coaching Por Competências (Linkedin.Com).

Guimarães, R. L. S., Garanhani, M. L., Souza, S. N. D. H., \& Haddad, M. C. L. (2018). Trabalho em equipe na formação do enfermeiro: perspectivas e desafios sob a ótica do pensamento complexo. Revista de Ensino, Educação e Ciências Humanas, 19(4), 465-471. 10.17921/2447-8733.2018v19n4p465-471

Kreling, A., \& Magalhães, A. M. M. (2018). Medication administration - nursing workload in clinical Inpatient units. Cogitare Enfermagem, 23(1):e50974. 10.5380/ce.v23i1.50974

Lei $n^{\circ} 10.216$ de 6 de abril de 2001. Dispõe sobre a proteção e os direitos das pessoas portadoras de transtornos mentais e redireciona o modelo assistencial em saúde mental. Presidência da República, Subchefia para assuntos jurídicos. L10216 (planalto.gov.br).

Lima, M. M., Machado, M. L., Costa, R., Canever, B., Pina, J. C., \& Alves, I. F. B. O. (2018). Contribuição da extensão em um grupo de gestantes e casais grávidos para a formação do enfermeiro. Escola Anna Nery Revista de Enfermagem, 22(4), e20170367. 10.1590/2177-9465-EAN-2017-0367.

Jalles, M. P., Santos, V. S. J., \& Reinaldo, A. M. S. (2017). Análise da produção científica sobre comunicação terapêutica no campo da saúde, saúde mental e álcool e outras drogas. Revista de Medicina (São Paulo), 96(4):232-240. 10.11606/issn.1679-9836.v96i4p232-240

Kang, K. I., \& Joung, J. (2020). Outcomes of Consumer Involvement in Mental Health Nursing Education: An Integrative Review. International Journal of Environmental Research and Public Health, 17(6756), 01-18. 10.3390/ijerph17186756.

Medeiros, E. S. M., Prestes, D. R. M., Pignata, E. K. A. A., \& Furtado, R. M. S. (2018). Perfil do enfermeiro docente e sua percepção sobre a formação pedagógica. Revista Recien - Revista Científica de Enfermagem, 8(24), 42-53. Recuperado de: Perfil do enfermeiro docente e sua percepção sobre a formação pedagógica | Medeiros | Revista Recien - Revista Científica de Enfermagem.

Mendes, A. C., Marques, M. I., Monteiro, A. P., Barroso, T., \& Quaresma, M. H. (2018). Education in mental health and psychiatry nursing in the undergraduate nursing course. SMAD, Revista Eletrônica Saúde Mental Álcool e Drogas, 14(2), 73-83. 10.11606/issn.1806-6976.smad.2018.000366

Miranda, S. (2012). Oficina de dinâmica de grupos para empresas, escolas e grupos comunitários. (10a ed.). Papirus e 7 Mares editora. (Coleção Catálogo Geral).

Moscovici, F. (2008). Desenvolvimento Interpessoal: treinamento em grupo. (14a ed.). José Olympio.

Munari, D. B., Costa, H. K., Cardoso, A. H. A., \& Almeida, C. C. O. F. (2003). Características da competência interpessoal do enfermeiro: estudo com graduandos de enfermagem. Revista Brasileira de Enfermagem, 56(5), 484-487. 10.1590/S0034-71672003000500003

Munari, D. B., \& Furegato, A. R. (2003). O enfermeiro como coordenador de grupos. In Munari D. B, Furegato A. R. F. (Orgs.). Enfermagem e grupos. (2a. ed.).

Nóbrega, M. P. S. S., Venzel, C. M. M., Sales, E. S., \& Próspero, A. C. (2020). Ensino de enfermagem em saúde mental no Brasil: perspectivas para a atenção primária à saúde. Texto \& Contexto Enfermagem, 29(e20180441), 01-13. 10.1590/1980-265X-TCE-2018-0333

Nunes, F. C., Caixeta, C. C., Pinho, E. S., Souza, A. C. S., \& Barbosa, M. A. (2019). A tecnologia grupal no cuidado psicossocial: um diálogo entre pesquisaação e educação permanente em saúde. Texto \& Contexto Enfermagem, 28(e20180161), 01-13. 10.1590/1980-265X-TCE-2018-0161

Pedrochi Júnior, O., Carvalho, D. F., Silva, T. T. F., \& Costa, N. M. L. (2021). Avaliação da aprendizagem no ensino superior: reflexões em uma perspectiva andragógica. Revista de Ensino, Educação e Ciências Humanas, 22(1), 43-51. 10.17921/2447-8733.2021v22n1p43-51

Pinheiro, C. W., Araújo, M. A. M., Rolim, K. M. C., Oliveira, C. M., \& Alencar, A. B. (2019). Teoria das relações interpessoais: reflexões acerca da função terapêutica do enfermeiro em saúde mental. Enfermagem em foco, 10(3), 64-69. http://revista.cofen.gov.br/index.php/enfermagem/article/view/2291/580.

Pinho, E. S., Nunes, F. C., Vale, R. R. M., Sousa, J. M., \& Silva, N. S. (2019). Grupo operativo como estratégia do processo de ensino aprendizagem. Revista Gepesvida, 5(11), 14-29. http://www.icepsc.com.br/ojs/index.php/gepesvida/article/view/345

Queiroz, J. G. P. (1997). O equilíbrio do temperamento através da música. Editora Cultrix.

Rocha, R. M., Kestenberg, C. C. F., Oliveira, E. B., Silva, A.V., \& Nunes, M. B. G. (2003). Construindo um conhecimento sensível em saúde mental. Revista Brasileira de Enfermagem, 56(4), 378-380. 10.1590/S0034-71672003000400013

Rocha, B. S., Munari, D. B., Sousa, B. M., Leal, M. L., \& Ribeiro, L. C. M. (2019). Ferramentas do coaching no desenvolvimento da liderança da enfermagem 
Research, Society and Development, v. 10, n. 12, e117101220057, 2021

(CC BY 4.0) | ISSN 2525-3409 | DOI: http://dx.doi.org/10.33448/rsd-v10i12.20057

na atenção primária à saúde. Revista de Enfermagem da UFSM, 29(e46), 01-23. 10.5902/2179769234762

Rodrigues, J., Lazzari, D. D., Martini, J. G., \& Testoni, A. K. (2019). Ensino da saúde mental em enfermagem na percepção de professores. Texto \& Contexto Enfermagem, 28(e20170012), 01-11. 10.1590/1980-265X-TCE-2017-0012

Rosseto, R. (2012). Jogos e improvisação teatral. UNICENTRO. Recuperado de ARTES_Robson (unicentro.br).

Saeki, T., Munari, D. B, Alencastre, M. B, \& Souza, M. C. B.M. (1999). Reflexões sobre o ensino de graduação em enfermagem na dinâmica de grupo. Revista da Escola de Enfermagem da USP, 33(4), 342-347. 10.1590/S0080-62341999000400003

Santana, L. L., Beljaki, W. D., Gobatto, M., Haeffner, R., Antonacci, M. H., \& Buzzi, J. A. P. (2018). Estresse no cotidiano de graduandos de enfermagem de um instituto federal de ensino. RECOM - Revista de Enfermagem do Centro Oeste Mineiro, 8(e2738), 01-11. 10.19175/recom.v8i0.2738

Silva, F. F., \& Ramos, K. M. C. (2017). Pós-graduação stricto sensu em Administração: profissionalização para o magistério superior em questão. Revista de Estudios e Investigación en Psicología y Educación, extr. (6), 01-05. 10.17979/reipe.2017.0.06.2261

Souza, K. L. (2017). O uso do lego serious play como estratégia de treinamento organizacional. Trabalho de Conclusão de Curso. Universidade Federal do Paraná, Paraná. R - E - KARINA LEITAO DE SOUZA.pdf (ufpr.br).

Sousa, K. H. J. F., Gonçalves, T. S., Silva, M. B., Soares, E. C. F., Nogueira, M. L. F., \& Zeitoune, R. C. G. (2018). Riscos de adoecimento no trabalho da equipe de enfermagem em um hospital psiquiátrico. Revista Latino-Americana de Enfermagem, 26(e3032), 01-10. 10.1590/1518-8345.2458.3032

Tavares, C. M. M., Pastor Júnior, A. A., Paiva, L. M., \& Lima, T. O. (2021). As inovações no processo ensino-aprendizagem da enfermagem psiquiátrica e saúde mental. Revista Brasileira de Enfermagem, 74(suppl. 5). 10.1590/0034-7167-2020-0525

Ward-Griffin, E., Klaiber, P., Collins, H. K., Owens, R. L., Coren, S., \& Chen, F. S. (2018). Petting away pre exam stress: The effect of therapy dog sessions on student wellbeing. Stress and Health, 34(3), 468-473. 10.1002/smi.2804. 